\title{
Interactive communication between the user and the computer-aided design system of shaft forging on presses
}

\author{
Sergey Kanyukov ${ }^{1}$, Anatoly Konovalov ${ }^{1}$, and Olga Muizemnek ${ }^{1, *}$ \\ ${ }^{1}$ Institute of Engineering Science, Ural Branch of the Russian Academy of Sciences, Ekaterinburg, \\ Russia
}

\begin{abstract}
Despite the accelerated development of computer technology, programming languages and methods in recent years, computer-aided design of open-die forging on presses is still not widespread due to weak formalization of the subject area. Therefore, the developers of relevant computer-aided systems have to put "approximate" algorithms and programs into the systems for solving technological problems. As a result, they provide users with the ability to adjust design concepts by a graphic dialogue. The paper describes a mechanism of interactive communication between the user and the computer-aided design system of shaft forging on presses, which was developed at the Institute of Engineering Science of the Russian Academy of Sciences (Ural Branch). This system provides wide opportunities for making necessary adjustments in a forging drawing and a forging process map. This ensures obtaining necessary design and process documentation suitable for using in the production process, even when the algorithms and programs are imperfect. Moreover, it significantly facilitates the implementation of the system at various enterprises.
\end{abstract}

One of the ways to increase productivity in the forging industry is the use of computeraided design of technological processes. These computer-aided process planning (CAPP) systems can significantly reduce the development time and improve the quality of design concepts. The experience of developing first CAPP systems in the field under consideration was described in $[1,2]$. In recent years, the development of CAPP for forging on hammers and presses has been continued [3, 4].

At the same time, it should be noted that the computer-aided design of open-die forging has not been properly developed, since this subject area is poorly formalized. Even now, the developers of relevant CAPP systems still have to put "approximate" algorithms and programs to the systems for solving technological problems. As a result, they have to provide users with the ability to adjust design concepts by a graphical dialogue. Therefore, the development of reasonable and user-friendly mechanisms of interactive communication between the user and the CAPP system is crucial.

The need for the development of a natural-language user interface for CAPP systems was emphasized in [5]. The issues of the user's communication with software and

\footnotetext{
*Corresponding author: olga@imach.uran.ru
} 
development of friendly, intuitively understandable interfaces of software products were discussed in [6]. An overview of existing design patterns, which are used for creating a user interface, was given in [7]. An example of a user interface for sheet metal forming was discussed in [8]. There are no examples of a user interface of CAPP systems for forging on presses in the literature.

A computer-aided process planning system for shaft forging on presses (Tekhnolog) has been developed at the Institute of Engineering Science, Ural Branch of the Russian Academy of Sciences (Ekaterinburg) [9]. This system executes the following functions:

- inputting initial information about a forged part;

- designing a forged part;

- designing a technological process of forging;

- obtaining design concepts in the form of design and process documentation (a working drawing of a forged part, a forging process map).

It is possible for the user to adjust the solutions offered by the system at all stages of design.

The aim of this work is to describe principles of interactive user communication with the system in the frame of the Tekhnolog CAPP user interface. The length of the paper does not allow us to make a full description of the interface; therefore, only the main points are considered.

The Tekhnolog CAPP implements forging design in two stages. At the first stage, the design is carried out in automatic mode, according to which the input information on a forged part from a design drawing is converted into a working drawing of a forging (Fig. 1) and a forging process map (Fig. 2).

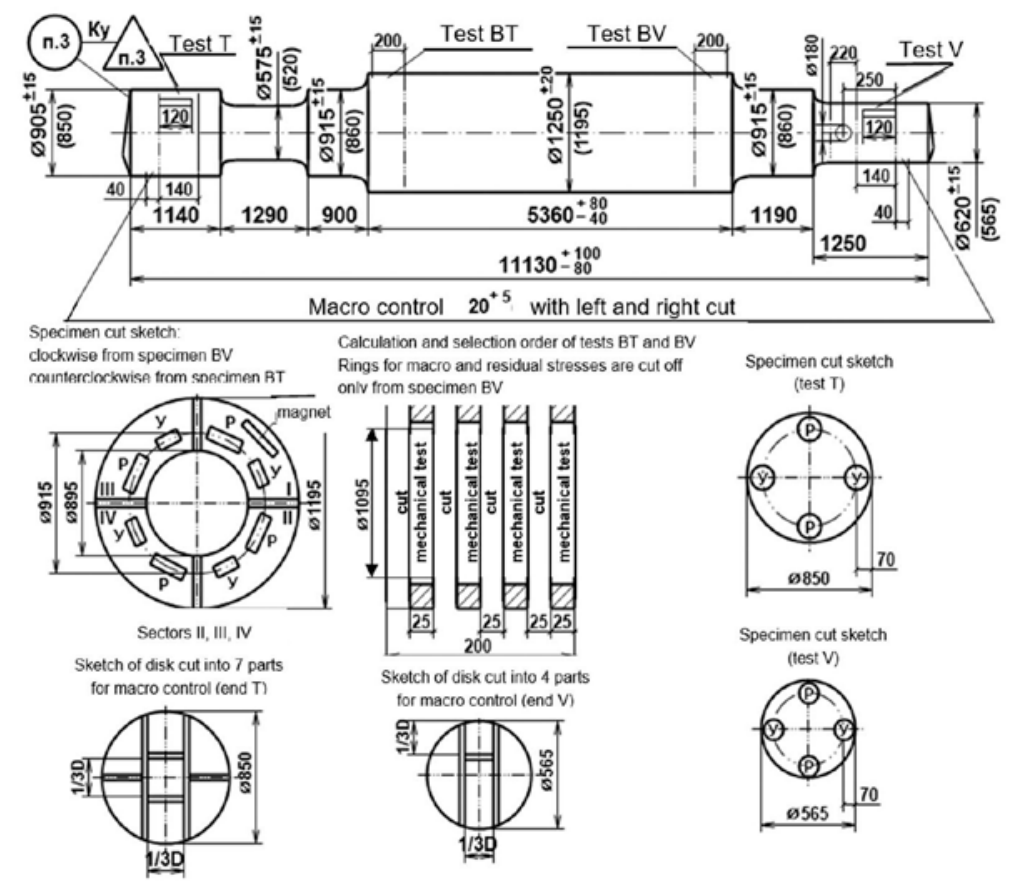

Fig. 1. A fragment of a working drawing of a forging (parenthesized dimensions are finished forging dimensions with heat treatment tolerances). 


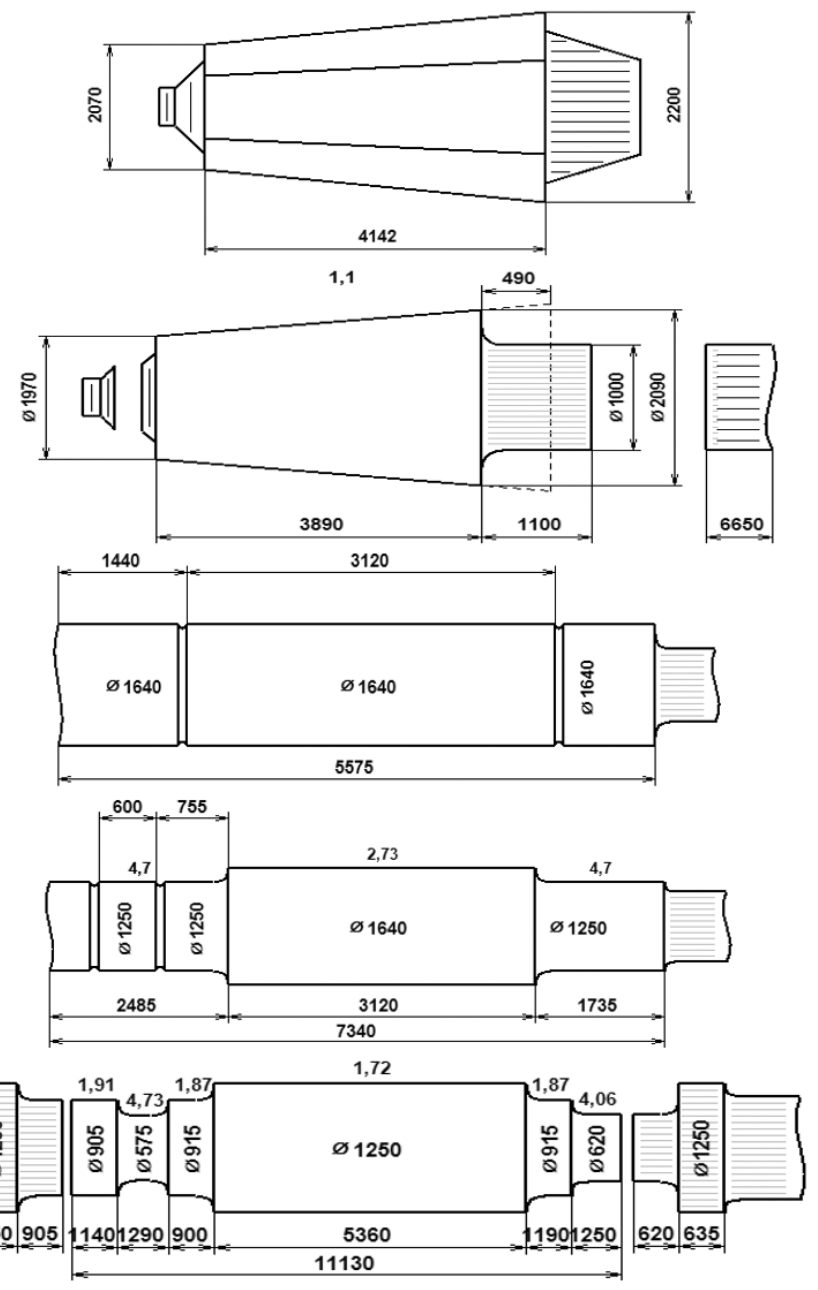

Fig. 2. A fragment of a forging process map.

If the design concept obtained by the Tekhnnolog CAPP does not suit the user, the second stage is executed. It is adjustment of the results obtained in automatic mode by the user's effects on these results.

All possible effects are divided into technological and graphical. Graphical effects are associated with the preparation of design (see fig. 1) and process (see fig. 2) documentation. The user can select the drawing format and to enter, delete, move or combine graphic and text objects or their elements in these documents. A specialized graphic editor was developed in [10] to implement the graphical effects in the Tekhnolog CAPP.

The technological effect $V$ consists in changing the value $x$ of this or that process variable, which, as a rule, demands to redesign the working drawing of the forging and (or) the technological process of forging. The processing of this effect $V(x)$ includes primarily its checking for syntax, correctness and acceptability.

Check for syntax. The check is executed when the value of a parameter is typed by the user on the keyboard rather than selected from the list offered by the system. Let us assume that, if the effect $V(x)$ passes the syntax checking, an event $A$ occurs. Then the actions of 
the system related to check for syntax can be described using the apparatus of mathematical logic as follows:

$$
\begin{gathered}
V(x) \wedge \bar{A} \Rightarrow \text { effect } V(x) \text { is removed, } \\
V(x) \wedge A \Rightarrow \text { effect } V(x) \text { is checked for correctnes s. }
\end{gathered}
$$

Check for correctness. The check is executed to ensure that the input value $x$ lies within the confidence interval of its values $x \in\left[x_{\min }, x_{\max }\right]$. The $x_{\min }$ and $x_{\max }$ limits of the confidence interval for each parameter are determined by the general forging design rules $[1,2]$ and technological instructions of enterprises. For example, for the forging presented in fig. 1, $x_{\min }$ and $x_{\max }$ values are $x_{\min }=520 \mathrm{~mm}$ and $x_{\max }=915 \mathrm{~mm}$ for the diameter $x=520 \mathrm{~mm}$ of the second stage from the left. Let us assume that, if the effect $V(x)$ passes the check for correctness, an event $B$ occurs. The actions of the system are described by the expressions

$$
\begin{gathered}
V(x) \wedge \bar{B} \Rightarrow \text { effect } V(x) \text { is checked for acceptability } \\
V(x) \wedge B \Rightarrow \text { effect } V(x) \text { is accepted. }
\end{gathered}
$$

Check for acceptability. The analysis of forging process maps shows that sometimes technologists make decisions that are slightly different from technological instructions; however, these decisions still allow one to produce a suitable forging. Therefore, it is necessary to provide the user with the ability to make adjustments with a valid exit beyond the limits $x_{\min }$ and $x_{\max }$ of the confidence intervals, i.e, for each $x$, it is also necessary to determine the limits $x_{\min }^{\mathrm{lim}}<x_{\min }$ and $x_{\max }<x_{\max }^{\mathrm{lim}}$ of the acceptable interval.

For example, for the top first workpiece (ingot) presented in fig. 2, when adjusting the length $x=435 \mathrm{~mm}$ of left waste, the boundary values of the confidence and acceptable intervals, defined by the system, are as follows: $x_{\min }^{\lim }=58 \mathrm{~mm}, x_{\min }=116 \mathrm{~mm}$, $x_{\max }=1073 \mathrm{~mm}, x_{\max }^{\lim }=1129 \mathrm{~mm}$.

Let us assume that, if the effect $V(x)$ passes the check for acceptability, an event $C$ occurs. Then system actions are described by the expressions

$$
\begin{aligned}
& V(x) \wedge \bar{C} \Rightarrow \text { effect } V(x) \text { is removed, } \\
& V(x) \wedge C \Rightarrow \text { effect } V(x) \text { is accepted }
\end{aligned}
$$

Combining the expressions (1-3), we obtain a formalized description of the mechanism of interactive user communication with the Tekhnolog CAPP in the following form:

$$
\left\{\begin{array}{c}
V(x) \wedge[\bar{A} \vee \bar{C}] \Rightarrow \text { effect } V(x) \text { is removed, } \\
V(x) \wedge A \wedge \bar{B} \wedge C \Rightarrow \text { effect } V(x) \text { is accepted (with remarks), } \\
V(x) \wedge A \wedge B \wedge C \Rightarrow \text { effect } V(x) \text { is accepted (without remarks) }
\end{array}\right.
$$

Since all the parameters of the process are interrelated, changing most of them requires to redesign the process taking into account the effects accepted earlier. In this case, it may prove to be that the latest effect will conflict with the previously accepted effects. For example, the user changed the dimensions of the workpieces (see fig. 2) and then decided to change the ingot. It is obvious that the system should remove all the previous effects and 
adopt the latest one, since ingot selection is the most important step in the forging process design. This step determines the concepts of solving all other problems. Therefore, for each effect, its own status (a numerical indicator of its relative importance) is determined, its relationships with other possible effects being established. The following rule of communication is accepted in the Tekhnolog CAPP for a couple of interrelated effects: from two mutually exclusive effects we select the one with a higher status; in case of status equality, we select the latest accepted effect. This issue is considered in more detail in [11, 12].

\section{Conclusion}

A concept of interactive communication between the user and the computer-aided system of shaft forging on presses has been developed and implemented as software. The system provides an operational check of effects for the syntax, correctness, acceptability and redesign of the forging process in view of the compatibility of these effects with previously accepted effects. The proposed mechanism of interactive communication allows much room for making necessary adjustments of a working drawing of a forging and a forging process map. This ensures that, even if the developed algorithms and programs are imperfect, the necessary design and process documentation suitable for the production process can be obtained. Moreover, this kind of communication significantly facilitates the implementation of the system at various enterprises.

The work was done according to the Program of the Ural Branch of the Russian Academy of Sciences, project No. 18-1-1-13.

\section{References}

1. V.N. Trubin, S.D. Shalyagin, S.N. Orlov [et al.] Avtomatizatsiya proektirovaniya tekhnologii kovki na molotakh (Mashinostroenie, Moscow, 1974)

2. A.N. Gavrilov, S.V. Skorodumov, Teoriya i praktika avtomatizatsii proektirovaniya tekhnologicheskikh protsessov (Mashinostroenie, Moscow, 1974)

3. A.V. Konovalov, S.V. Arzamastsev, S.D. Shalyagin, O.Yu. Muizemnek, P.Yu. Gagarin, Blanking Productions in Mechanical Engineering, 1, pp. 20-23 (2010)

4. N.E. Vozmishchev, Computer-Aided Design in Machine Industry, 3, pp. 43-453 (2015)

5. I.A. Bessmertny, R.V. Posevkin, Software \& Systems, 3, pp. 5-9 (2016)

6. V.V. Gribova, N.N. Cherkezishvili, Information Technologies, 10, pp. 54-58 (2010)

7. B.B Mayvan., A.Rasoolzadegan, Z.G. Yazdi, Journal of Systems and Software, 125, pp. 93-118 (2017)

8. V.G. Kovalev, A.V. Rybakov, Blanking Productions in Mechanical Engineering, 4, pp. 30-33 (2007)

9. S.I. Kanyukov, A.V. Konovalov, O.Yu. Muizemnek, Yu.V. Khalevitsky, A.S. Partin, Software, Systems \& Algorithms, 3 (2017) DOI: 10.15827/2311-6749.24.262.

10. O.Yu. Muizemnek, A.V. Konovalov, P.Yu. Gagarin, Software \& Systems, 2, pp. 148$151(2011)$

11. S.I. Kanyukov, A.V. Konovalov, Software \& Systems, 3, pp. 126-131 (2014)

12. S.I. Kanyukov, A.V. Konovalov, Fundamental Research, 2(14), pp. 3039-3043 (2015) 